\title{
Improving Teaching Style with Dialogic Classroom Teaching Reform in a Chinese High School
}

\author{
Xiaojin Kang ${ }^{1} \&$ Jing Han ${ }^{2, *}$ \\ ${ }^{1}$ Shanghai Nanhui High School, Shanghai, China \\ ${ }^{2}$ Department of Physics, The Ohio State University, Columbus, Ohio, USA \\ *Correspondence: Department of Physics, The Ohio State University, Columbus, Ohio, USA. E-mail: \\ han.286@osu.edu
}

Received: February 20, 2019

Accepted: March 17, 2019 Online Published: March 27, 2019

doi:10.5430/wje.v9n2p38

URL: https://doi.org/10.5430/wje.v9n2p38

\begin{abstract}
Lively and effective classroom instruction is an important feature of quality schools. Recently, the lead author's school has launched a reform of classroom teaching methods to implement a dialogic model. The dialogic model, taking cues from constructivist learning theories and Manabu Sato, expects educators to promote multiple kinds of classroom dialogue, including teacher-student dialogue, student-text dialogue, student-student dialogue, and self-reflective dialogue. The reform efforts of the school are all-encompassing and include changes to teacher training, classroom observation and teaching evaluation, lesson planning, classroom activities, homework, and testing. This reform is meant to improve teaching quality, enhance the classroom environment, and bring about better critical thinking outcomes in the students. The following text chronicles the details of this reform in a large senior high school in a Chinese metropolis, and the first attempts by teachers at the school to implement new dialogic teaching techniques. The preliminary analysis finds evidence of positive effects on student engagement, confidence, and motivation using dialogic teaching techniques.
\end{abstract}

Keywords: dialogic teaching, dialogue, attentive listening, teaching reform

\section{The Purpose and Significance of the Research}

Creating a more effective classroom teaching environment that encourages students to think critically and share their own ideas is a crucial issue in Chinese education reform. In China, Confucian values make students generally unwilling to challenge the teacher or the author of a text directly, and students are tentative about sharing their ideas in front of the whole class (Fung, 2014; Wang \& Seepho, 2017). The traditional curriculum concept in China, based on behaviorism, has made students' critical thinking ability and initiative relatively weak (Tian \& Low, 2003; Zhou, Wang, \& Yao, 2007). As realized in the classroom, behaviorism dictates that learning is a process of stimulation and response that does not consider the students' mental state. The goal of education in this model is to convey objective knowledge that learners receive, so that their knowledge matches what the educator possesses. The most common form of dialogue in this model is a one-way lecture from the individual teacher to a group of students, without a lot of meaningful interaction (Yilmaz, 2011; Liu \& Matthews, 2005). Under this way of communication - which sees a monopoly on dialogue by the educator - educators are loyal to lifeless things like disciplines and knowledge, at the expense of building a trusting relationship between them and their students. Teachers are just as passive as the recipient students as they merely transmit knowledge created by others (Zhong, 2006). Therefore, there is an urgent need to construct a new classroom teaching culture in Chinese public school that allows students and teachers to create knowledge for themselves and engage in meaningful dialogue. The administrators at Shanghai Nanhui High School (hereafter, SNHS), a large public high school in Shanghai, China, have determined that, in order to push back against the traditional model and help students develop in-demand critical thinking and reasoning skills, a new classroom teaching culture must be established.

In this new era of Chinese education, we must focus more on the needs of individual students and transform the traditional teaching-centered classroom environment into a learning-centered one. The teaching and research activities of our school need to focus on building a learning community that allows everyone to contribute. We believe that the 
best way to improve our students' thinking and learning skills is to carry out a dialogic classroom teaching reform. Under the premises of democracy and equality, dialogic teaching is based on the many forms of dialogue that can occur in the classroom: the dialogue between students and teachers, between students and students, between students and texts, and between the student and his or her inner self. Dialogic classroom instruction allows students to bring their own ideas into the lesson and engage with their own personal experiences (Zhong, 2006; Wells \& Arauz, 2006; Mercer \& Littleton, 2007).

We believe dialogic teaching is the best way to encourage our students to be active learners and creators of their own knowledge, to achieve sustainable improvements in our students' critical and creative thinking, and to prepare them to be better workers in a global, multicultural environment. While long-term measurements of these kinds of improvements in our students are beyond the scope of this paper, what we will introduce here is the first stages of our efforts to achieve truly dialogic education at our school and create a sustainably growing learning community. We hope the teaching, training, planning, and evaluation methods described below can inspire other Chinese schools to use similar techniques.

\section{Defining Dialogic Teaching}

To conceptualize dialogic teaching as we would attempt to implement it in our school, we turned to Japanese educator Sato. According to Sato, schools in the 21st century should be "schools that learn with the community" in which administrators, teachers, students, and parents all contribute to learning. To create such a school, he strongly advocates the transformation of regular classroom teaching. Firstly, he notes that, in traditional classrooms, students usually sit in rows and rely solely on brain cell activities to receive information. The new way of learning he proposes requires students to engage in learning through physical interactions and dialogue by performing activities like surveys, experiments, and discussions. Then, Sato points out that, in the traditional classroom, students' learning is usually a solitary activity. Students rarely engage in cooperative learning through interaction and teamwork. In the new way, learning is interactive and cooperative with different types of group and pair work. Last, in the traditional classroom, the students' learning is mainly reflected in the acquisition of predetermined knowledge and skills with right and wrong answers. Under the new style, students create their own knowledge by sharing and communicating with the instructor and their peers. They reflect personally on the knowledge and skills they have learned. There are still benchmarks and goals, but students figure out knowledge on their own instead of being told all the answers (Sato, 2003a). These characteristics define the dialogic classroom for our purposes.

Further, the equal consciousness of the interlocutors is the prerequisite and key to sustainable and effective dialogue. Dialogic teaching gives both teachers and students a personal right to speak. But, in the implementation of dialogic teaching, how does the teacher ensure that students enact this right to speak? First of all, teachers are required to perform attentive listening, so that they pay attention to and respect the point of view of each student. They must let students feel brave enough to speak, teach them to ask questions, and help them get to the bottom of what they are learning about. Teachers should dial into students' feelings and become an active guide who induces dialogue. Moreover, as teachers and students develop their common dialogue, it brings everyone into a state of mutual trust and deep thinking. The role of the teacher is not the transmitter of knowledge but the facilitator of student learning. The teacher transitions from the "soloist" to the "accompanist." It is no longer the main goal of the teacher to impart knowledge, but to help students discover, organize, and manage knowledge, to guide them instead of shaping them (UNESCO, 1996).

As the teachers listen attentively and make sure students are using their right to speak, they must also monitor their own dialogue. Sato gives us guidelines for how teachers should "speak" in the teacher-student dialogue. The teacher's speech generally falls into the following four types: structural discourse, inductive discourse, reflective discourse, and responsive discourse. Structural discourse sets the scene and theme of the dialogue and keeps the discourse on task. The discourse should generally take the form of a question string, wherein both students and teachers are asking and answering questions about the material in order to get to the bottom of the topic. The teacher's response to questions should be timely and accurate and lead to induction on the part of the students. The teacher's inductive discourse does not tell the students the correct answer immediately but leads the student through further questioning to realize how to find the answer by themselves. Reflective discourse is the guidance the teacher gives to allow the students to evaluate a topic, agree with the material, and express their opposition. Lastly, through responsive discourse, teachers should be able to present their own opinions in a realistic manner, and accept objections to their points of view, because in the dialogic classroom, everyone is equal before the truth (Sato, 2003b). Ideally, students become active individuals participating together in an open, democratic, and relaxed classroom atmosphere. 


\section{The Practice of Dialogic Classroom Teaching Reform at SNHS}

\subsection{The Main Goals of Dialogic Classroom Teaching Reform}

Considering the definition of a truly dialogic classroom presented in the previous section, the dialogic classroom teaching reform as conceived by our administrators must provide firm support to quality education, and promote the comprehensive, healthy, and sustainable development of students. The reform must be based on two platforms: a conceptual platform that provides necessary theoretical knowledge about dialogic teaching, and a practical platform that guides the application of new dialogic teaching techniques in our classrooms. It must also strive to make breakthroughs in these areas: inspiration of dialogic thinking in our teachers, innovations in classroom teaching procedures, integration of new styles of classroom activities, creation of new kinds of homework activities and new test designs, and enhanced teacher training and evaluation methods to ensure dialogic teaching is being implemented.

\subsection{Developments in Teacher Training to Encourage Dialogic Teaching Style}

To realize the dialogic transformation in classroom teaching, administrators at SNHS decided we must first introduce the dialogic teaching style to our teachers through new trainings. We define "teaching style" as the set of teaching strategies and methods developed by individual teachers in long-term educational practice. It is a comprehensive expression of teachers' educational philosophy, awareness of educational theory, and handle on practical skills. As administrators, it is our responsibility to implement training that will build the teaching styles we want to see in our classrooms.

In order to promote dialogic teaching in our instructors and re-establish the training and research culture of our school to fit the dialogic model, we felt it necessary to encourage significantly more dialogue in our teacher trainings. In the old style, senior teachers presented techniques for newer teachers to absorb, and while the participants in the trainings could ask questions or give feedback, we did not expect much critical thinking from them. In our trainings on dialogic teaching, we decided to try a new style of training based on teacher-to-teacher dialogue.

To achieve this dialogue between teachers, we have standardized open-house classroom observations and required teachers to open their doors to colleagues. Each teacher has open-house classes once or twice per year depending on their seniority. After the open houses are completed, both the classroom teacher and the observers complete reflective follow-up activities. These activities are generally discussions based on feedback forms that focus on the teacher's style and the apparent attitudes and achievements of the students.

Supervisors will provide individual classroom improvement plans to the teachers based on the results of these observations and discussions, as well as base their future trainings on the weak points identified in the observations and discussions. Some of our new training activities include asking teachers to analyze a lesson plan and find more opportunities to induce student dialogue, having teachers design a group work activity that achieves a given teaching objective, or imagine a conversation a student might have between himself/herself and the text. Ultimately, through this combination of observation and training, we hope our teachers will have more research and experience to draw on in order to help students learn better, allowing everyone to become a research-oriented teacher.

\subsection{Outlining Guidelines to Help Teachers Speak and Listen in a Dialogic Fashion}

In the classroom, the dialogue between teachers and students is a process of exploring and discovering truth together. In order to enter into fruitful dialogue with the students, the teacher must perform attentive listening. To perform attentive listening, the teacher listens to the students' perceptions, frustrations, and "why" and "how" questions. Then, according to the specific situation in the classroom, the teacher uses various methods to help students solve their problems, organize what they are learning, and make new discoveries based on the material (Tan, 2002).

Under the dialogic classroom teaching reform, our school has come up with the "Daily Questions of Classroom Teaching." These "Questions" are guidelines that help our teachers make sure they are thinking and teaching in a dialogic fashion and aiming to dispel student doubts through shared learning and communication. The Daily Questions are as follows:

- Are the teacher and all of the students listening to each other in the classroom?

- Did the teacher really listen to the students before organizing their ideas and eliciting students to think and speak?

- Is the teacher sensitive and does he/she pay close attention to the students' individual learning situations?

- Does the teacher's language and behavior correspond to the changing classroom learning dynamic?

- Does the teacher take advantage of every opportunity to let the students engage with the text? 
- In the face of students' problems and doubts, does the teacher focus on the students with one heart and one mind, and use all available methods to address their concerns?

- In classroom teaching, does the teacher focus his or her energy on in-depth observation of each student, and propose specific learning tasks to induce students to learn more profoundly?

\subsection{Transformation of Lesson Planning and Classroom Activities}

In order to bring fruitful dialogue into the classroom teaching process, teachers must use activities that will inspire different kinds of dialogue. We have been training our teachers on diverse teaching methods that will lead to successful dialogue. Whole-class discussions let students share their own ideas with guidance from the instructor, who can lead them in the right direction and help organize their thoughts. Student-to-student dialogue is encouraged by small group discussion, group writing activities, scientific experiments, and creative projects. In these situations, students can demonstrate their abilities to express themselves, communicate with each other, and cooperate productively. Student-to-text dialogue happens during activities like silent reading and reflection, note-taking, and writing questions for the author. These activities allow students to understand and interpret texts from a multidimensional perspective. Lastly, students must be given opportunities for self-dialogue in a process of self-reflection that allows the student to consider what he or she has learned and how it changes his or her understanding of the world.

These activities are valued not only because they promote dialogue, but because they promote trust between the teachers and students, the students and their classmates, and the students and themselves. Through this trust, the teachers and students all help each other, and the teacher becomes the cultivator of student growth (Tan, 2002). We want to add that, though one-way lectures from the teacher to the students should not constitute the whole class, they can still be used to introduce new material or bring the students back on task after an activity.

Under our dialogic teaching reform, we have been expecting our teachers to include such methods in their lesson plans. In the process of writing and implementing their teaching plans, teachers must fully consider the possibilities for all different kinds of dialogue, and how those kinds of dialogue will help achieve the learning objectives.

\subsection{Transformation of Homework and Testing Styles}

Administrators have selected a teaching and research group for each discipline at our school to design homework activities and grading rubrics that will also promote dialogic thinking in our students. The goal is for homework not to just reinforce the classroom teaching content, but to complement it by letting students think even more deeply. This includes more creative exercises and self-reflective journals, where students are encouraged to think of their own ideas more than they are judged for the journal content.

The teaching and research groups are also working on guidelines for evaluating dialogic thinking in quizzes and tests. Instead of multiple choice, fill-in-the-blank, or true/false questions, we are testing out more short-answer questions, essay questions, and open-ended questions that might be able to assess students' capacity for critical thinking and dialogue.

\subsection{Reorientation of Evaluation Criteria to Reflect Dialogic Teaching Expectations}

The main target for assessment in our classroom teaching evaluations under the dialogic teaching reform is the learning situation of the students. To structure this assessment, we have identified four main points for evaluators to consider: First, is the content of the class consistent with the content of the lesson plan? Second, does the content of the lesson focus on the main learning objectives? Third, are the teacher's comments and suggestions targeted toward helping students achieve the desired objectives? And fourth, is the teacher regularly helping students to learn independently while addressing their doubts, blind spots, and difficulties?

The administrators are designing evaluation rubrics that help analyze classes from a critical perspective based on these key points: teaching objectives, teaching content, teaching methods, teaching organization, and teacher-student relationship. The teaching objectives should reflect cognitive objectives, operational skill objectives, and socio-emotional objectives. The selection of teaching content should be appropriate for the teaching objectives and should be in line with students' ability to absorb and understand the material. The teaching methods used determine whether the instructor can mobilize enthusiasm and initiative in the students. The methods should inspire different forms of dialogue. Teaching organization refers to the pacing of the class and whether the teacher has left time for students to learn, practice, and review the material. As for the relationship between teachers and students in the classroom, evaluators hope to see the teachers address students' problems and doubts. The teacher should concentrate on the needs of each student and closely observe their reactions and expressions in order to adjust the plan in real-time if need be. If all the above points are in sync, then the teacher can achieve a "first among equals" relationship with the 
students. For our classroom teaching reform, this is the ideal teacher-student relationship.

To help teachers prepare their lessons and feel confident during evaluations, we have prepared this list of key questions to pay attention to in classroom teaching:

- What are the most recently updated teaching objectives for my discipline? What resources and activities will help me achieve them?

- Does my lesson plan consider... 1) The three domains of teaching objectives (cognitive objectives, operational skill objectives, and socio-emotional objectives), 2) dialogic teaching, and 3) collaborative learning?

- Am I caring about the students' emotional states?

- Am I connected with the way my students think, and how to promote quality thinking in my students?

- Have I read the text thoroughly? Am I prepared to help the students read and interpret the text creatively?

- What skills and knowledge do my students already possess that will help them in this lesson, and what skills and knowledge are they lacking that need further development?

- What are the difficulties and obstacles the students might have in studying this material?

- Do I understand why I want to teach this material, and am I teaching it in the best way?

What we are asking for is not "perfect" classroom teaching. The evaluation does not expect or require the lesson to be without fault or leave no room for improvement. Our main concern is the students' learning and the continued professional development of our staff.

\subsection{Emphasizing Self-Reflective Dialogue in Students and Teachers Through Learning Summaries}

After each unit of classroom instruction, we will begin to ask students to summarize what they have learned, and teachers to summarize how well they feel their students have absorbed the material. The student summaries are a chance to both show their own unique knowledge of the disciplines they study and their own emotional reactions to the material. Each student's summary is a momentary scan of the student's learning status. The teacher's summary reflects the teacher's sentiment and understanding of his or her own teaching skills and the capabilities of his or her students. We feel that, through this last stage, we can better assess the inner psychological state of the students. At the same time, in the process of summarizing, teachers and students evaluate their own learning and conduct in-depth dialogues with themselves. The summary phase provides an excellent opportunity for teachers and students to generate common expectations and values, and to focus on the process of achieving future goals.

\section{Examples of the Implementation of Dialogic Teaching at SNHS and the Perceived Effect on Student Learning}

The path to effective implementation of dialogic teaching involves allowing students to try new classroom activities that give them opportunities to begin and sustain multiple kinds of dialogue. These activities should also allow them to master certain skills and abilities like group discussion, planning and implementation of a project, personal reflection on the meaning of texts, and asking and answering questions with the instructor. In this section, we present some examples of how our teachers have recently implemented dialogic teaching techniques in their classroom, and the effects on the students observed by colleagues and administrators:

\subsection{Letting Students Imagine the Ending to a Short Story}

Before studying O'Henry's short story The Last Leaf, a language arts teacher set up a segment of the class called "You say, I say." The teacher told the students the beginning and middle of the short story's plot, and let the students use their previous knowledge about O'Henry's style to imagine the ending. After the students shared their own opinions, the teacher briefly commented on their ideas, and then told them the end of the story. In this activity, students first used inductive discourse to come up with ideas on their own, then discussed their ideas with their tablemates, then exchanged their ideas with the whole class, and finally received the teacher's feedback. Some students' ideas coincided with O'Henry's actual ending, and the others came up with their own interesting interpretations. While the students were working, the teacher walked around the room and provided reflective discourse to help the students reflect on their ideas. The activity included teacher-student dialogue, student-student dialogue, and student-text dialogue. The students' excitement during the exercise was palpable, and the teacher's choice of activity greatly enhanced student enthusiasm for studying the short story in class. 


\subsection{Having Students Perform Their Own Interpretations of a Famous Drama}

When studying drama, our students are often not interested in the classical masterpiece The West Chamber, due to its formal literary style that they have little patience to read. When teaching this drama, another language arts teacher let students research and perform the play themselves in the classroom. Students first translated the text into common vernacular, and then added their own creative ideas in staging and props. Students had to be quite familiar with the text in order to speak and intone correctly during their performances. They also used the internet to research costumes and the historical period in which the play was written. They had to work effectively in a group in order to rehearse and plan. The students created and performed their presentations with enthusiasm. Their scores on exam questions about The West Chamber were quite high as well, and it appears that this method of teaching drama was very successful.

\subsection{Inviting "Little Teachers" to the Front of the Mathematics Classroom}

Several mathematics teachers in our school have begun to hold special sessions during which the students become "little teachers." After reviewing the material, the students write their own math problems and teach them to their classmates. In teaching the material themselves, the students often make mistakes, but the teacher uses these errors as opportunities for inductive discourse by analyzing the problem and letting the students figure out the solutions by themselves. Letting students teach each other also helps make sure the material stays in their long-term memories. Changes like this have brought about a small revolution in mathematics teaching at our school and greatly increased the efficiency of the math classrooms. Through dialogue with themselves, the whole class, and the teacher, students are able to comprehend the mathematics methods and improve their self-reflection ability. Furthermore, by observing the lectures given by the "little teachers," the teacher can assess the students' understanding of the mathematical principles and diagnose areas where students need more revision. This is the process by which teachers and students jointly produce expectations and values, and work together to achieve goals.

\subsection{Seizing the Moment When a Surprise Occurrence Can Lead to Effective Teacher-Student Dialogue}

In a speech class, one student told a traditional story to his classmates: "I will tell you a story about a race between a tortoise and a hare..." The student, in quite dry language, told the old tale, and at the end of the speech, called on everyone not to be as arrogant as the hare, and to work hard like the tortoise. On that day, the teacher did not give immediate feedback on the student's speech as he normally would have, but instead just imitated the student's dry tone of voice: "I will tell you a story about a race between a tortoise and a hare..." Some of the classmates laughed and thought that the teacher was just lightly making fun of the speaker. But, the teacher went on to say, "This time the hare learned his lesson, did not feel too proud and did not sleep in the shade of the tree. He ran to the finish line quickly. However, the result of the race is that the hare still lost. What is the reason?"

The students felt baffled and suddenly the atmosphere in the classroom became a bit serious. After a few seconds, the teacher drew a circular picture on the blackboard, and explained that the venue of the race was a pond. The start and finish were the two ends of the pond, and the tortoise swam through the middle as the hare ran around the pond. "Therefore," the teacher pointed out, "as long as you think seriously like the tortoise, you can also win by relying on strategy. Whether you are studying a particular subject or hearing a small lecture before class, you must learn to think and be good at thinking." After that day, to inspire more creativity in student speeches, the teacher has imagined unconventional speech topics, such as telling a traditional story with the student's own twist ending. Students' enthusiasm for giving and hearing speeches has improved, and the quality of the speeches has improved significantly. This example shows that teachers should be good at seizing the precious educational resources that lie within spur-of-the-moment thoughts and ideas and use their structural discourse to create educational opportunities and improve the effectiveness of classroom dialogue.

\section{Analysis and Conclusion}

The preliminary efforts to bring about the dialogic classroom teaching reform described above have shown promising results. Students are embracing the variety of dialogues that occur with partners, small groups of different sizes, and whole-class activities. In our school, where class sizes can exceed 40, these different group sizes give every student a chance to speak. Though students may be shy about speaking in front of a large group due to their Confucian cultural heritage, they can get used to sharing their thoughts and opinions in small groups first. Through class observations, we have found that achieving effective dialogue requires students to feel confident, and different group sizes help achieve that end.

Student confidence also develops through the trusting relationships that dialogic teaching techniques create. By having a more open and democratic classroom and expecting our teachers to pay more attention to students' emotional states 
and reactions, true relationships develop in which students and teachers care about each other. We believe that when students are in that environment of caring, they feel freer and more confident to speak. For example, when the students' become little teachers in the math classroom, they feel confident because they know the teacher supports them and can help guide the class. When students perform their plays, they feel confident because they had discussions with the whole class, the teacher, and their small group members beforehand during which they shared and tested their ideas.

The sheer variation of classroom activities we are seeing at our school has also shown great promise. The dialogic teaching activities that let students change desks, move around, explore, and talk to their peers have led to great improvements in the self-reporting of enthusiasm in informal student comments and notes made by observers. Giving students a chance to work together and be creative gives them a greater stake in what they are doing. Instead of parroting knowledge, they can be truly creative, which we hope will improve their critical thinking skills and motivation to learn.

We have also seen firsthand that, while the democratic ideals of dialogic teaching reform are lofty, there are often roadblocks in encouraging dialogue. In the "Tortoise and the Hare" example, the students were notably uncomfortable when the teacher asked them to explain his twist ending. But, through correct attentive listening, the teacher was able to figure out that he had to explain the answer himself to really teach his point effectively. As another example of discomfort, though it was not observed during the open house class, the language arts teacher studying The West Chamber reported that, in the early stages of the project, many students were shy about performing, or unsure about how to translate the play into their own words. But, with small group discussions and guidance from the teacher, students were able to figure out how to best assign roles in the play to take advantage of everyone's strengths. We believe those moments of discomfort are what lead to truly effective dialogue and the trusting relationship between teacher and students. If the teacher performs attentive listening and pays close attention to the students, then he or she can work to dispel the discomfort. For true "learning with the community" to occur, we feel that these moments of discomfort should not be avoided but embraced as learning opportunities. Recall that the main goal of our evaluations is to see the teachers focus on student learning and improve professionally; we understand that it will not always be a smooth process.

The dialogic classroom teaching reform that we have begun is a great first step in the process of changing the culture of our entire school. As our reform continues, we want to start collecting more data on the effects dialogic teaching has on our students' motivation and performance, including student self-reflections and test results. We hope that, in the future, our school can continue to be a "school that learns with the community" that inspires our students, teachers, and administrators to create knowledge and share it with each other.

\section{References}

Fung, D. (2014). The influence of ground rules on Chinese students' learning of critical thinking in group work: A

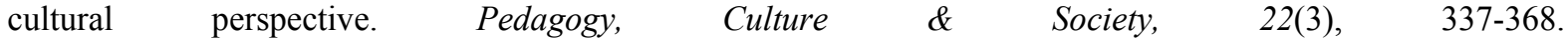
https://doi.org/10.1080/14681366.2014.899611

Liu, C. H., \& Matthews, R. (2005). Vygotsky's philosophy: Constructivism and its criticisms examined. International Education Journal, 6(3), 386-399.

Mercer, N., \& Littleton, K. (2007). Dialogue and the development of children's thinking: A sociocultural approach. London, England: Routledge. https://doi.org/10.4324/9780203946657

Sato, M. (2003a). 静悄悄的革命 [Silent Revolution] (J.Y. Yu, Trans.). Changchun, China: Changchun Press. (Original work published in 2000 in Japanese)

Sato, M. (2003b). 课程与老师 [Curriculum and Teachers] (Q.Q. Zhong, Trans.). Beijing, China: Education and Science Press. (Original work published in Japanese)

Tan, X. C. (2002). 人与人的对话 [Dialogue Between People]. Hefei, China: Anhui Education Press.

Tian, J., \& Low, G. D. (2011). Critical thinking and Chinese university students: A review of the evidence. Language, Culture and Curriculum, 24(2), 61-76. https://doi.org/10.1080/07908318.2010.546400

UNESCO. (1996). 教育——财富蕴藏其中 [Education - Wealth is hidden in it]. (UNESCO Headquarters, Trans.). Beijing, China: Education Science Press.

Wang, S., \& Seepho, S. (2017). Facilitating Chinese EFL Learners' Critical Thinking Skills: The Contributions of Teaching Strategies. SAGE Open. https://doi.org/10.1177/2158244017734024 
Wells, G., \& Arauz, R.M. (2006). Dialogue in the classroom. Journal of the Learning Sciences, 15(3), 379-428. https://doi.org/10.1207/s15327809jls1503_3

Yilmaz, K. (2011). The Cognitive Perspective on Learning: Its Theoretical Underpinnings and Implications for Classroom Practices. Clearing House: A Journal of Educational Strategies, Issues and Ideas, 84(5), 204-212. https://doi.org/10.1080/00098655.2011.568989

Zhong, Q. Q. (Ed.). (2006). 对话教育一国际视野与本土行动 [Dialogic Education: International Vision and Local action]. Shanghai, China: East China Normal University Press.

Zhou, Q., Wang, X., \& Yao, L. (2007). A preliminary investigation into critical thinking of urban Xi'an high school students. Frontiers of Education in China, 2(3), 447-468. https://doi.org/10.1007/s11516-007-0036-5 